\title{
EFICÁCIA DO CARFENTRAZONE-ETHYL APLICADO NO MANEJO DAS PLANTAS DANINHAS PARA O PLANTIO DIRETO DO ALGODÃO
}

\author{
Fernando Tadeu de Carvalho ${ }^{1}$, Sérgio Luiz A. Alvarenga², \\ Maximilian Peruchi ${ }^{3}$ e Rodrigo Rodrigues B. Palazzo ${ }^{3}$
}

\footnotetext{
${ }^{1}$ Eng ${ }^{\circ}$. Agrônomo, Dr., Professor. FEIS/UNESP. Av. Brasil, 56. Caixa Postal 31. Ilha Solteira, SP 15385-000. ftadeu @ bio.feis.unesp.br

${ }^{2}$ Eng ${ }^{\circ}$. Agrônomo. FMC do Brasil Indústria e Comércio S/A. Av. Dr. Moraes Sales, 711 - 30 andar. Campinas, SP $13010-910$.

${ }^{3}$ Graduando de Agronomia. FEIS/UNESP.
}

\begin{abstract}
RESUMO
O objetivo foi avaliar a eficácia do herbicida carfentrazone-ethyl em mistura com o glyphosate, no manejo de plantas daninhas em pós-emergência no plantio direto e avaliar os efeitos tóxicos sobre a cultura do algodão. O experimento foi desenvolvido no período de janeiro a março de 2001, na FEP-UNESP no município de Selvíria, MS, enquadrada em região de Cerrado, no sudeste do Mato Grosso do Sul, em solo com textura argilosa. O cultivar de algodão utilizado foi o 'ITA-90', com $0,90 \mathrm{~m}$ de espaçamento. O delineamento experimental utilizado foi o de blocos ao acaso, com seis tratamentos e quatro repetições. Os tratamentos foram os seguintes: 2,4-D (670 g/ha), flumioxazin ( $25 \mathrm{~g} / \mathrm{ha}$ ) e carfentrazone-ethyl $(20,25 \mathrm{e} 30 \mathrm{~g} / \mathrm{ha})$, todos com glyphosate e óleo mineral $(0,5 \% \mathrm{v} / \mathrm{v})$ e testemunha no limpo. As aplicações foram realizadas com um pulverizador manual e pressão constante de $3,2 \mathrm{kgf} / \mathrm{cm}^{2}\left(\mathrm{CO}_{2}\right)$, com barra equipada com quatro bicos tipo leque, espaçados de $0,5 \mathrm{~m}$ e volume de calda de $250 \mathrm{~L} / \mathrm{ha}$. Concluiu-se que os tratamentos carfentrazone-ethyl ( $20,25 \mathrm{e} 30 \mathrm{~g} / \mathrm{ha}), 2,4-\mathrm{D}$ ( $670 \mathrm{~g} / \mathrm{ha})$ e flumioxazin ( $25 \mathrm{~g} / \mathrm{ha})$, adicionados ao glyphosate $(960 \mathrm{~g} / \mathrm{ha})+$ óleo mineral $(0,5 \% \mathrm{v} / \mathrm{v})$, aplicados antes da semeadura do algodão, no manejo de plantas daninhas para o plantio direto, são eficientes no controle de Commelina benghalensis e Ipomoea nil e são seletivos às plantas de algodão, cultivar 'ITA-90'.
\end{abstract}

Palavras-chave: 2,4-D, flumioxazin, glyphosate, Gossypium hirsutum, interferência.

\section{ABSTRACT \\ Efficacy of carfentrazone-ethyl applied in the control of weeds in no-till cotton}

The objective was to evaluate the efficacy of the herbicide carfentrazone-ethyl in mixture with glyphosate, in the control of weeds in a no tillage system and to evaluate the tolerance of the cotton crop. The experiment was developed in the period from January to March of 2001, in the FEP-UNESP in Selvíria, MS, in soil with a loamy texture. The cultivar of cotton used was 'ITA-90', with $0.90 \mathrm{~m}$ of spacing. The experimental design was randomized block with six treatments and four replicates. The treatments were the following: 2,4-D (670 g/ha), flumioxazin ( $25 \mathrm{~g} / \mathrm{ha})$ and carfentrazone-ethyl (20, 25 and $30 \mathrm{~g} / \mathrm{ha})$, all with glyphosate and mineral oil $(0.5 \% \mathrm{v} / \mathrm{v})$ and a weed free control. The application was carried out with a manual pulverizer under constant pressure of $45 \mathrm{lb} / \mathrm{in}^{2}\left(\mathrm{CO}_{2}\right)$, with a bar equipped with four fan type nozzles, spaced $0.5 \mathrm{~m}$ apart and spray volume of 250 $\mathrm{L} / \mathrm{ha}$. The treatments carfentrazone-ethyl (20, 25 and $30 \mathrm{~g} / \mathrm{ha}), 2,4-\mathrm{D}$ (670 g/ha) and flumioxazin (25 g/ha), added to glyphosate $(960 \mathrm{~g} / \mathrm{ha})+$ mineral oil Assist $(0.5 \% \mathrm{v} / \mathrm{v})$, applied before cotton plantation, were efficient for the control of Commelina benghalensis and Ipomoea nil for the weed control in a no tillage system and selective for cotton plants, for cultivate 'ITA-90' .

Key words: 2.4-D, flumioxazin, glyphosate, Gossypium hirsutum, interferência. 


\section{INTRODUÇÃO}

As condições edafoclimáticas destacam o Brasil como um país de grande potencial para o cultivo do algodão. Entretanto, o clima tropical é também muito favorável à ocorrência de uma grande quantidade de plantas daninhas, que interferem no desenvolvimento e na produção das culturas. Os efeitos negativos detectados no crescimento e produtividade da cultura do algodão, devidos à presença das plantas daninhas, já foram observados por vários autores (Laca-Buendia et al., 1978 e 1979; Laca-Buendia \& Pires, 1992; Foloni et al., 1999).

As perdas mundiais de produção de fibras de algodão por ano, devido à competição com as plantas daninhas são de $5 \%$; porém, no clima tropical do Brasil, as perdas podem chegar a $71 \%$ (ANDEF, 1987). Segundo Blanco (1985) as perdas de produção do algodoeiro devido à concorrência com as plantas daninhas podem ser de $70-95 \%$ e o período crítico de competição ocorre entre os 25 e 50 dias do ciclo da cultura.

Uma das tecnologias utilizadas na cultura do algodão é o cultivo sem o revolvimento do solo. A prática do plantio direto, tem como principal vantagem, a conservação do solo. No entanto, um dos principais problemas que se tem detectado no sistema é a ocorrência de plantas daninhas e suas interações com o ambiente, prejudicando as plantas cultivadas.

Em áreas de plantio direto é muito freqüente a ocorrência de plantas daninhas nas diferentes fases do sistema de cultivo. Antes da implantação da cultura é necessário realizar a operação de manejo, com o objetivo de controlar as plantas daninhas. O controle das infestantes depende da eficiência do herbicida utilizado. O herbicida glyphosate é um dos mais utilizados na operação de manejo, entretanto, sua alta eficiência no controle de gramíneas não é observada no controle de algumas latifoliadas, necessitando, muitas vezes, do complemento de outros herbicidas. O carfentrazone-ethyl pode ser uma opção para a operação de manejo de plantas daninhas em áreas de ocorrência de plantas de folhas largas.

O objetivo do trabalho foi avaliar a eficácia agronômica do herbicida carfentrazone-ethyl aplicado em pós-emergência das plantas daninhas, na operação de manejo para o plantio direto e avaliar os efeitos fitotóxicos sobre a cultura do algodão (Gossypium hirsutum).

\section{MATERIAL E MÉTODOS}

O experimento foi desenvolvido no período de janeiro a março de 2001, na Fazenda de Ensino e Pesquisa (FEP) da UNESP - FEIS, localizada no município de Selvíria, MS, enquadrada em região de Cerrado, no sudeste do Mato Grosso do Sul. O solo da área experimental é classificado como Latossolo Vermelho-Escuro, textura argilosa, com $45 \%$ de argila, $2 \%$ de silte e $53 \%$ de areia. A semeadura foi realizada mecânicamente em 04/01/2001 no sistema "plantio direto sobre o mato" e o cultivar de algodão utilizado foi o 'ITA-90', com 0,90 m de espaçamento.

Os tratos culturais realizados na área experimental, foram os normais exigidos pela cultura no que diz respeito às adubações e ao controle de pragas e doenças. As adubações foram realizadas concomitantemente à semeadura, utilizando-se a

Tabela 1. Tratamentos utilizados no experimento. FEP, Selvíria, MS. 2001.

\begin{tabular}{|c|c|c|}
\hline \multirow{2}{*}{ Tratamento } & \multicolumn{2}{|c|}{ Dose dos Herbicidas } \\
\hline & i.a. $(\mathrm{g} / \mathrm{ha})^{2}$ & p.c./ha ${ }^{3}$ \\
\hline 1- Testemunha no limpo & - & - \\
\hline 2-2,4-D + glyphosate + óleo mineral' & $670+960$ & $1,0 \mathrm{~L}+2,0 \mathrm{~L}$ \\
\hline 3- Flumioxazin + glyphosate + óleo mineral ${ }^{1}$ & $25+960$ & $50 \mathrm{~g}+2,0 \mathrm{~L}$ \\
\hline 4- Carfentrazone + glyphosate + óleo mineral' & $20+960$ & $50,0 \mathrm{~mL}+2,0 \mathrm{~L}$ \\
\hline 5- Carfentrazone + glyphosate + óleo mineral' & $25+960$ & $62,5 \mathrm{~mL}+2,0 \mathrm{~L}$ \\
\hline 6- Carfentrazone + glyphosate + óleo mineral' & $30+960$ & $75,0 \mathrm{~mL}+2,0 \mathrm{~L}$ \\
\hline
\end{tabular}

${ }^{1}$ Concentração do óleo mineral $=0,5 \%$ v $/ \mathrm{v}$

2 i.a. $=$ ingrediente ativo

${ }^{3}$ p.c. $=$ produto comercial

Tabela 2. Características dos produtos utilizados no experimento. FEP, Selvíria, MS. 2001.

\begin{tabular}{|c|c|c|c|c|c|}
\hline Nome técnico & Nome comercial & $\begin{array}{c}\text { Concentração } \\
{\text { (i.a. })^{1}} \\
\end{array}$ & Formulação & Grupo químico & $\begin{array}{c}\text { Classe } \\
\text { toxicológica }\end{array}$ \\
\hline $2,4-\mathrm{D}$ & DMA 806 BR & $670 \mathrm{~g} / \mathrm{L}$ & SAq & fenóxiacéticos & $\mathrm{I}$ \\
\hline Flumioxazin & Flumyzin 500 & $500 \mathrm{~g} / \mathrm{kg}$ & PM & ftalimidas & III \\
\hline Carfentrazone-ethyl & Aurora $400 \mathrm{CE}$ & $400 \mathrm{~g} / \mathrm{L}$ & $\mathrm{CE}$ & aril triazolinonas & II \\
\hline Óleo mineral & Assist & $756 \mathrm{~g} / \mathrm{L}$ & Óleo emulsionável & hidrocarbonetos & IV \\
\hline Glyphosate & Roundup & $480 \mathrm{~g} / \mathrm{L}^{2}$ & CS & derivados da glicina & IV \\
\hline
\end{tabular}

1 i.a. $=$ ingrediente ativo

2 glyphosate $=360 \mathrm{~g} / \mathrm{L}$ equivalente ácido 
fórmula comercial 8-28-16 + 0,3\% de zinco à base de $250 \mathrm{~kg} / \mathrm{ha}$, e adubação de cobertura, aos 40 dias após a semeadura, com a fórmula $20-0-20$ a $220 \mathrm{~kg} / \mathrm{ha}$.

Os herbicidas selecionados para o teste experimental (Tabelas 1 e 2) foram aplicados na operação de manejo em pósemergência das plantas daninhas, dois dias antes da semeadura da cultura. Em todos os tratamentos químicos foi adicionado o óleo mineral Assist na dose de 0,5\% v/v. Não foi realizado o controle de plantas daninhas em pós-emergência da cultura, com o intuito de não se confundir o efeito dos herbicidas aplicados na dessecação.

O delineamento experimental adotado foi o de blocos ao acaso, com seis tratamentos e quatro repetições. As parcelas foram dimensionadas com $4 \mathrm{~m}$ de comprimento e $5 \mathrm{~m}$ de largura, totalizando $20 \mathrm{~m}^{2}$.

As aplicações dos herbicidas foram realizadas com um pulverizador costal, com pressão constante $\left(\mathrm{CO}_{2}\right)$ de $3,2 \mathrm{kgf} /$ $\mathrm{cm}^{2}$, provido de tanque com capacidade de dois litros (garrafas descartáveis), e com barra equipada com quatro bicos do tipo leque, marca Teejet 110.03 (XR), espaçados de $0,5 \mathrm{~m}$. O volume de calda aplicado foi de $250 \mathrm{~L} / \mathrm{ha}$. As aplicações foram realizadas em pós-emergência das plantas daninhas, no dia 04/01/2001. Na ocasião o solo encontrava-se com umidade, em decorrência das chuvas ocorridas nos dias anteriores; a temperatura do ambiente, marcada no início, foi de $29^{\circ} \mathrm{C}$ e a umidade relativa do ar de $72 \%$; ventava pouco, próximo à superfície, sendo a velocidade do vento inferior a $4 \mathrm{~km} / \mathrm{h}$.

A eficiência dos herbicidas no controle das plantas daninhas foi avaliada aos 21 e 35 dias após a aplicação (DAA) dos tratamentos. Utilizou-se uma escala visual onde $0 \%=$ nenhum controle e $100 \%$ = controle total das plantas daninhas. Considerou-se como eficiente o controle superior a $80 \%$. As avaliações de seletividade foram realizadas aos 7, 14 e 21 dias após a aplicação (DAA) dos tratamentos. Para se determinar o efeito fitotóxico dos herbicidas utilizou-se a escala em percentagem, onde $0 \%=$ nenhuma injúria e $100 \%=$ morte da cultura. $O$ efeito dos tratamentos no estande da cultura foi avaliado aos 60 dias após a semeadura, contando-se o número de plantas em $2 \mathrm{~m}$ na linha central das parcelas.

\section{RESULTADOS E DISCUSSÃO}

A infestação das plantas daninhas na área experimental, em avaliação realizada imediatamente antes da aplicação dos herbicidas, foi de $40 \%$ de cobertura do solo por plantas de Commelina benghalensis (trapoeraba) e de 55\% por Ipomoea nil (corda-de-viola), ambas em fase juvenil. Outras espécies que ocorreram com níveis de infestações menores que $10 \%$, durante todo o ciclo, não foram consideradas.

C. benghalensis e Ipomoea spp. ocorrem freqüentemente em lavouras dos Estados de São Paulo e Paraná. Em áreas de plantio de algodão, ambas as espécies foram observadas juntas (Foloni et al., 1999; Garcia, 1999).

A planta daninha trapoeraba tem se destacado em áreas de plantio direto, pela sua frequência e por ser considerada planta de difícil controle (Marochi, 2000). Na cultura do algodão, a espécie foi recentemente relatada por Constantin et al. (2000). Em outras culturas, nesse sistema de cultivo, foi observada também por Maciel \& Constantin (2000), Rosseto et al. (2000), Adegas et al. (2000), Garcia \& Nascimento (2000), Mascarenhas \& Lara (2000), Pereira \& Carmona (2000) e Carvalho \& Cavazzana (2000).

O tratamento carfentrazone-ethyl + glyphosate foi eficaz no controle de Commelina benghalensis. Nas doses de 20,25 e $30 \mathrm{~g} / \mathrm{ha}$ de carfentrazone-ethyl, os tratamentos proporcionaram controles totais $(100 \%)$ da planta daninha aos 35 DAA (Tabela 3 ). Os resultados observados estão de acordo com Lorenzi (2000), com relação a eficácia do carfentrazoneethyl no controle de plantas adultas de trapoeraba.

O tratamento $2,4-D+$ glyphosate $(670+960 \mathrm{~g} / \mathrm{ha})$ foi eficaz no controle de $C$. benghalensis, proporcionando média de controle de $95 \%$, aos 35 DAA. O tratamento flumioxazin + glyphosate $(25+960 \mathrm{~g} / \mathrm{ha})$ também foi eficaz no controle de C. benghalensis, proporcionando média de controle de $85 \%$, aos 35 DAA.

Com relação a Ipomoea nil todos os tratamentos foram altamente eficazes, proporcionando controles totais (100\%), aos 35 DAA.

Tabela 3. Controle de Commelina benghalensis e Ipomoea nil. FEP, Selvíria, MS. 2001.

\begin{tabular}{lcccrr}
\hline \multirow{2}{*}{ Tratamento } & Dose & \multicolumn{2}{c}{$\begin{array}{c}\text { Controle de } \\
\text { C. benghalensis (\%) }\end{array}$} & $\begin{array}{c}\text { Controle de } \\
\text { Ipomoea nil (\%) }\end{array}$ \\
\cline { 3 - 6 } & (g/ha) & 21 DAA & 35 DAA & 21 DAA & 35 DAA \\
\hline Testemunha no limpo & - & 0 & 0 & 0 & 0 \\
2,4-D + glyphosate & $670+960$ & 95 & 95 & 100 & 100 \\
Flumioxazin + glyphosate & $25+960$ & 90 & 85 & 100 & 100 \\
Carfentrazone-ethyl + glyphosate & $20+960$ & 100 & 100 & 100 & 100 \\
Carfentrazone-ethyl + glyphosate & $25+960$ & 100 & 100 & 100 & 100 \\
Carfentrazone-ethyl + glyphosate & $30+960$ & 100 & 100 & 100 \\
\hline
\end{tabular}

DAA = Dias após a aplicação dos herbicidas 
Fernando Tadeu de Carvalho et al.

Tabela 4. Fitotoxicidade dos herbicidas e estande da cultura do algodão. FEP, Selvíria, MS. 2001.

\begin{tabular}{lccc}
\hline \multicolumn{1}{c}{ Tratamento } & Dose (g/ha) & Fitotoxicidade (\%) & No de plantas/m \\
6, 14 e 21 DAA & DAS \\
\hline Testemunha no limpo & - & 0 & 8,0 \\
2,4-D + glyphosate & $670+960$ & 0 & 7,5 \\
Flumioxazin + glyphosate & $25+960$ & 0 & 9,0 \\
Carfentrazone-ethyl + glyphosate & $20+960$ & 0 & 8,0 \\
Carfentrazone-ethyl + glyphosate & $25+960$ & 0 & 8,5 \\
Carfentrazone-ethyl + glyphosate & $30+960$ & 0 & 8,5 \\
\hline Média Geral & & & 8,2 \\
Teste f (tratamentos) & & & $0,36^{\mathrm{ns}}$ \\
Coeficiente de Variação (\%) & & 21,1 \\
DMS (5\%) & & & 3,9 \\
\hline
\end{tabular}

DAA = Dias após a aplicação dos herbicidas.

DAS = dias após a semeadura

Obs.: teste de Tukey a 5\% de probabilidade

Os tratamentos com o herbicida carfentrazone-ethyl não provocaram sintomas de fitotoxicidade às plantas de algodão (Tabela 4). Este fato pode ser explicado devido à modalidade de aplicação do herbicida, na operação de manejo das plantas daninhas para o plantio direto, onde os herbicidas não entraram em contato direto com a cultura e devido ao fato do carfentrazone-ethyl não possuir efeito residual no solo. Os tratamentos com os herbicidas 2,4-D e flumioxazin também foram seletivos às plantas de algodão.

\section{CONCLUSÕES}

Os herbicidas carfentrazone-ethyl (20, 25 e $30 \mathrm{~g} / \mathrm{ha}), 2,4-$ D (670 g/ha) e flumioxazin (25 g/ha), adicionados ao glyphosate (960 g/ha) + óleo mineral Assist (0,5\% v/v), aplicados antes da semeadura do algodão, no manejo de plantas daninhas para o plantio direto, são eficientes no controle de Commelina benghalensis e Ipomoea nil e são seletivos às plantas de algodão, cultivar 'ITA-90'.

\section{LITERATURA CITADA}

ADEGAS, F.S.; GAZZIERO, D.L.P.; BRIGHENTI, A.M.; VOLL, E. Eficiência de herbicidas utilizados no manejo para a implantação da cultura da soja em plantio direto. In: CONGRESSO BRASILEIRO DA CIÊNCIA DAS PLANTAS DANINHAS, 22. Foz do Iguaçu, PR, 2000. Resumos... Londrina: SBCPD, 2000. p. 119.

ASSOCIAÇÃONACIONAL DEDEFENSIVOS AGRÍCOLAS - ANDEF. Defesa vegetal. São Paulo, SP: ANDEF, 1987. $19 \mathrm{p}$.
BLANCO, H.G. Ecologia das plantas daninhas - competição de plantas daninhas em culturas brasileiras. In: Controle integrado de plantas daninhas. $2^{\underline{a}}$ ed. São Paulo: CREA, 1985.p. 42 - 75.

CARVAlHO, F.T.; CAVAZZANA, M.A. Eficácia de herbicidas no manejo de plantas daninhas para o plantio direto de soja. Revista Brasileira de Herbicidas, Brasília, v.1, n.2, p. 167-172, 2000.

CONSTANTIN, J.; OLIVEIRA, JR., R.S; RAMIREZ, A.C.; MARCHIORI, JR., O.; MACIEL, C.D.G. Alternativas químicas para a operação de manejo na cultura do algodão. In: CONGRESSO BRASILEIRODA CIÊNCIA DAS PLANTAS DANINHAS, 22. Foz do Iguaçu, PR, 2000. Resumos... Londrina: SBCPD, 2000. p. 330.

FOLONI, L.L.; RODRIGUES, J.D.; ONO, E.O. Avaliação de tratamentos químicos e mecânicos no controle de plantas daninhas na cultura do algodão. Planta Daninha, Botucatu, SP, v. 17, n. 1, p. 5-20, 1999.

GARCIA, I. Eficácia e seletividade do clomazone, isoladamente e em misturas para controle das principais plantas daninhas na cultura do algodão. In: CONGRESSO BRASILEIRO DE ALGODÃO, 2. Ribeirão Preto, SP, 1999. Anais... Ribeirão Preto: EMBRAPA-CNPA, 1999. p. 623625.

GARCIA, I.; NASCIMENTO, E. Avaliação do herbicida carfentazone-ethyl (Aurora $400 \mathrm{CE}$ ) em mistura com glyphosate e sulfosate no controle de plantas daninhas em semeadura direta da soja. In: CONGRESSO BRASILEIRO DA CIÊNCIA DAS PLANTAS DANINHAS, 22. Foz do Iguaçu, PR, 2000. Resumos... Londrina: SBCPD, 2000. p. 121. 
LACA-BUENDIA, J.P. delC.; PURCINO, A. A. C.; FERREIRA, L.; FERRERIA, M.B. Competição de misturas de herbicidas nas principais regiões algodoeiras (Gossypium hirsutum L.) no Estado de Minas Gerais. Planta Daninha, Campinas, SP, v. 1, n. 2, p. 5-15, 1978.

LACA-BUENDIA, J.P. del C.; PURCINO, J.C.V.; FERREIRA, L. Período crítico de competição entre comunidades de plantas daninhas e o algodoeiro (Gossypium hirsutum L.) no Estado de Minas Gerais. Planta Daninha, Campinas, SP, v. 2, n. 2, p. 89-95, 1979.

LACA-BUENDIA, J.P del C.; PIRES, G.A.D. Avaliação da eficiência de controle de plantas daninhas gramíneas do herbicida clethodim em algodoeiro herbáceo (Gossypium hirsutum var. latifolium Hutch.). Planta Daninha, Brasília, DF, v. 10, n. 1 e 2, p. 50 - 54, 1992.

LORENZI, H. Manual de identificação e controle de plantas daninhas: plantio direto e convencional. $5 \mathrm{Ed}$. Nova Odessa, SP: Plantarum, 2000. 339 p.

MACIEL, C.D.G.; CONSTANTIN, J. Eficiência de sistemas de manejo em plantio direto e sua influência sobre herbicidas utilizados em pós-emergência na cultura da soja. In: CONGRESSO BRASILEIRODA CIÊNCIA DAS PLANTAS DANINHAS, 22. Foz do Iguaçu, PR, 2000. Resumos... Londrina: SBCPD, 2000. p. 112.
MAROCHI, A.I. Eficácia de glyphosate isolado ou em mistura no controle de Commelina benghalensis em aplicação de pré-plantio com complementação de glyphosate 30 dias após emergência da soja Roundup Ready. In: CONGRESSO BRASILEIRO DA CIÊNCIA DAS PLANTAS DANINHAS, 22. Foz do Iguaçu, PR, 2000. Resumos... Londrina: SBCPD, 2000. p. 174.

MASCARENHAS, M.H.T.; LARA, J.F.R. Avaliação da eficiência da mistura pronta de [imazethapyr + AC.303.757] aplicada em dessecação na cultura da soja. In: CONGRESSO BRASILEIRO DA CIÊNCIA DAS PLANTAS DANINHAS, 22. Foz do Iguaçu, PR, 2000. Resumos... Londrina: SBCPD, 2000. p. 122.

PEREIRA, R.C.; CARMONA, R. Eficácia do herbicida flumioxazin, isolado e em mistura com sulfosate, no manejo de plantas daninhas em plantio direto de soja. Revista Brasileira de Herbicidas, Brasília, v.1, n.2, p. 113118, 2000.

ROSSETO, J.; DUTRA, I.; SILVA, A.C.; BENATTI, F.V. Avaliação de herbicidas alternativos ao uso de 2,4-D associados à glyphosate na dessecação de áreas de pousio. In: CONGRESSO BRASILEIRO DA CIÊNCIA DAS PLANTAS DANINHAS, 22. Foz do Iguaçu, PR, 2000. Resumos... Londrina: SBCPD, 2000. p. 116. 